\title{
European legislation and incentives programmes for Demand Side Management
}

\author{
Maria de Fátima Castro ${ }^{a}$, Shane Colclough ${ }^{b}$, Bruno Machado $^{a}$, Joana Andrade ${ }^{a}$, \\ Luís Bragança ${ }^{a}$
}

${ }^{a}$ CTAC Universidade do Minho, Campus de Azurém, 4800-058 Guimarães, Portugal

b Centre for Sustainable Technologies - Room 26B16, Ulster University, Newtownabbey, BT37 0QB, UK

\begin{abstract}
Energy is now intrinsically linked to technological development, given it powers all such systems. The use of fossil fuels to supply the required energy is causing global environmental and health issues and is impacting on all life forms on the planet. Given increasing energy consumption, anthropogenic greenhouse gas emissions are consequentially increasing. Therefore, it is necessary to replace fossil fuels with renewable energies, biofuels and eco materials and related technologies and to try and find a way to develop sustainable zero emission solutions for all areas including constructions, transport and water resources.
\end{abstract}

A critical and evolutionary way of thinking about the energy (and other resource) demand, management and supply is necessary because there is a clear concern about irreversible impacts to the world and a scarcity of the resources as well. Energy supplies should be mostly or entirely through renewable resources and highly efficient technologies put in place to achieve solution such as nearly Zero Energy Buildings (nZEB).

At the same time, all the energy and resource use processes should be optimised in order to maximise the benefits, reduce the costs and promote stakeholders (consumers, companies or governments) network, toward a circular economy. This could be the way to supply the demand without increasing the scarcity of the resources and to simultaneously achieve environmental benefits. Therefore, it should be possible to improve productivity with the same amount of resources, by e.g. maximising the potential of smart grids and heuristically develop solutions with stakeholders.

The concept of Demand Side Management (DSM) emerged after the energy crisis and it employs solutions such as reducing the daily peak load. At the same time, creating an educational grid is important to change the established paradigms, in order to promote critical thinking about the wasted resources and thinking holistically about overall consumption. This paradigm shift is changing the market, making it more competitive and reducing inefficiency by promoting the efficient use of resources including deployment of energy storage during the periods of low consumption in daily peak shift.

All these issues present a new way of thinking in the path towards sustainability, maximising the circular economy and reducing environmental impacts, making connections and using the Internet of Things to provide more information to all stakeholders. All these changes in social behaviour are related to the rational use of resources and make it easier to improve the existing infrastructures instead of building new ones.

This paper analyses the state of the art at the European level in the production and use of renewable resources. A survey and analysis of the incentives to consumers and the policies to encourage the circular economy, and a parallel analysis of benefits and drawbacks, was made. It is intended to identify the main forms of intervention and improvement, culminating in a reflection on how they should be applied in order to improve the expected results and make them more efficient and sustainable. This is intended to be an evolutionary framework of this concept, from the first stage of use of energy to its final utilisation.

By approaching the task in a heuristic fashion, it is hoped to make the environment healthier, and it is envisaged that this concept will evolve from a linear to a life cycle approach.

Keywords:

Demand Side Management; Energy Storage; Circular Economy; Zero Emissions; Sustainability. 


\section{Introduction}

The building sector is one of the most resource-consuming sectors in the European Union. In their whole life cycle, from the extraction of materials, the manufacturing of construction products, construction, use and maintenance, buildings in the EU amount for approximately one half of all extracted materials and energy consumption, in addition to one third of water consumption and generated waste (EU, 2016). On the other hand, the building sector has also a significant impact at a social and economic level (Mateus and Bragança, 2011). This sector is estimated to be worth 10\% of global GDP and employs 111 million people (UNEP, 2016).

In the Roadmap to a Resource Efficient Europe, buildings are highlighted as one of three key sectors to be addressed. Better construction and use of buildings could deliver significant resource savings: $42 \%$ of final energy consumption; about $35 \%$ of total GHG emissions; $50 \%$ of the extracted materials; and up to $30 \%$ of water in some regions (Herczeg et al, 2014).

\section{How is the building industry dealing with the concept of Demand Side Management?}

"The concept of sustainable development has evolved into a guiding principle for a livable future world where human needs are met while keeping the balance with nature." (Barreto et al., 2003, pp.1).

On the other hand, the World Wildlife Fund (WWF) in their Living Planet Report (LPR) claim that if all the world lives like an average European, it 2.6 planets will be needed. At European Union (EU), buildings are responsible for $40 \%$ of final energy consumption and $36 \%$ of $\mathrm{CO} 2$ emissions according to the Energy Performance of Buildings Directive (EPBD) Directive 2010/31/EU of the European Parliament and of the Council.

Therefore, the EU is trying to develop policies and directives to ensure the growth of sustainable construction and improve the environmental performance of buildings throughout their whole life cycle. This includes promoting Eco-Design, including the concept of "Passivhaus", encouraging the use of local resources, proper orientation, natural lighting, smart materials like biopolymers with conductivity and thermal active mortars, insulation, double skin façades, energy efficient windows, and modular and prefab ways of construction which can be totally recycled, considering the all building life cycle (Kylili and Fokaides, 2017).

Design calculations should begin early when the design options can be explored and where the main carbon savings can be updated to decrease the environmental impacts during the life cycle of the construction, thereby promoting sustainability (Attia et al., 2012). There are therefore many Building Sustainability Assessment (BSA) methods to help all the stakeholders of the construction lifecycle quantifying inputs and outputs.

Unfortunately, the context of the companies involved in construction does not facilitate the establishment of the required concepts. It is inherently difficult for them to maximize their own progress with the use of models of the linear economy and achieve the required economic benefits resulting in a no-win scenario for the built environment (Din and Brotas, 2016).

The circular economy is a win-win scenario which saves the environment and stimulates the economy. The main goal of the circular economy is try to achieve a step change in education (Lazarevic and Valve, 2017).

Hence, all the stakeholders in the building life cycle should be educated to be able to focus on that which is truly important in order to avoid climate change and make the environment 
healthier. This involves promoting the circularity in closed cycles, showing the benefits and features in a way that should achieve the environmental goal of assuring the global health for future generations (Kylili and Fokaides, 2017).

However, nowadays there are a lot of technologies which can be applied in the buildings to improve energy efficiency by energy harvesting, thermal energy storage, penetration of renewables by the sun, wind and geothermal energy (on-site, off-site and nearby supply and load management) (Karunanithi et al., 2017). Furthermore, there is good interconnectedness between all of the elements. Therefore, with a dimensioned grid, efforts to reduce the demand in the peak periods and conserve energy during the less period demand, it will be possible to use or sell energy back during the peak hour ensuring a good pathway to demand response (Strbac, 2008).

Combined and dynamic tariffs designed to provide a win-win scenario can be applied by the energy service companies, which can be monitored and measured to achieve an improved paradigm in the way that construction companies manage the systems and resources. Therefore, it will be easier to supply the demand with the infrastructures already built and implement simple incentives for the consumers. The circular economy provides an industrial system that is restorative and regenerative by an early design stage considering the different building life cycle phases, providing a low carbon economy and a sustainable growth, maximizing the benefits and reducing the costs. In addition, it also delivers dynamic and interactive services and enable expert assistance, learning, and peer-to-peer sharing experiences to reduce human error (Bergaentzlé et al., 2014).

The concept of the Internet of Things (IoT) which can connect billions of devices, enabling sensors and monitoring of stakeholders from manufactures to governments and research labs, tracking and monitoring is pathways during the time of use. It can improve the efficiency with artificial intelligence with an automated demand, and connecting person to person, person to machine, machine to person and machine to machine (Vermesan and Friess, 2013).

Therefore, IoT can improve the 3D printed constructions. The process of construction can be almost done on-site which will reduce the necessity for the transportation of materials and manufacturing at the construction site, and reduce noise. It will decrease the need of all the resources and reduce wastes. Most of the resources needed can reuse in close cycles from the stakeholder in the building industry which improves the circularity and increase the energy efficiency, reducing the potential environmental impacts and improving social performance. With all of this is well done, it can provide considerable benefits in the pathway to sustainability and short returns on investment with longer term paybacks to the environment and the stakeholders (Duballet et al., 2017).

Finally, it takes more than money to produce disruptive pathways to achieve environmental, social and economic rewards. Unlocking habits and promoting innovation and healthier education, all these paradigms should be well-articulated to push forward efficiency to achieve a zero-carbon economy in the pathway to achieve the goals for the next decades from EU (Bragança et al., 2014).

\subsection{International policies and initiatives}

Buildings are one of the most significant ways to improve energy efficiency. Currently, in the EU, considering buildings under the Energy Efficiency Directive (EED), just under $\%$ of the buildings are well designed to meet the demand response of all the stakeholders during 
their life cycle. Almost $60 \%$ of space heaters are still inefficient and almost $40 \%$ of the windows still single glazed according to the EED Directive 2012/27/EU of the European Parliament and of the Council. This needs to be improved not only in the new buildings but also in the rehabilitation of buildings already constructed.

Hence, smart materials like biopolymers with conductivity and phase change materials like thermally active mortars should be included in the construction solutions in the envelope. Double skin façades, operable windows, natural lighting to reduce unnecessary electrical usage can therefore provide a healthier air quality inside and outside of the buildings (Rahimpour et al., 2017).

Demand response is crucial for meeting future energy needs with lower supply and transmission capacity, given that the eco-design work plan can be accompanied by storage technology and services. In particular, thermal energy storage systems will increase grid flexibility (Smale et al., 2017). Electrical energy cannot currently be stored in an effective way so it needs to be distributed and consumed in the most sustainable way, minimizing waste. So, the paradigm of Demand Side Management (DSM) is fundamental (Dabur et al., 2012). Hence, the consumers need to be engaged and to understand the value and conditions of the programmes, a cost-benefit analysis should be well understood with a benchmarking report (Smale et al., 2017).

Therefore, with the evolutionary and faster way of technology development, construction should be modular enough to readapting during its life cycle to find the pathway to a sustainable demolition process in the last building life cycle stage (Lehmann, 2013).

In the earlier design stages, eco-designers should provide a preliminary risk assessment which should be explicit and provide an initial and operational cost analysis. During the implementation stage this should be adapted based on circumstances and unfolding requirements. Continuous monitoring will be the key to sustainable management throughout the building life cycle because with an automated prediction, the grid provides a signal to the building and the building will respond. This will be an approach to make the system restorative and regenerative, rethinking the pathways to sustainability (Bragança et al., 2014).

However, buildings need energy throughout their life cycle, leading to embodied energy considerations; operational energy, Heating, Ventilation, \& Air Conditioning (HVAC) systems, manufacture, maintenance, demolition, auxiliary systems, appliances, and lighting. This could therefore promote the penetration of renewables energies which can either be onsite, nearby the building or off-site providing a real commercial and technological alternative to electrical usage and oil burning and subsequent fossil fuels (Muñoz et al., 2017).

Supplying innovation in terms of how buildings and all the stakeholders during all the construction lifecycle produce energy, transport it, deliver it to consumers and what services they offer, place consumers center stage, and support the competitiveness of European industry. This thereby enables a cooperative mechanism capable of achieving an innovative eco-system which in turn enables the attainment of the Paris Agreement.

Hence, technologies and services provide smart solutions to energy consumers that give control to the stakeholders to optimise their energy consumption, developing new materials and new technologies for building energy efficiency solutions. Furthermore, industrialized construction processes will be a win-win scenario for a sustainable development, modelling and prediction (Ford et al., 2017). 
Applying efficient solutions like building and subsystems control and efficient lighting, promotes solutions which make use of artificial intelligence with smart meters and monitoring facilitated with automated technologies. Hence the grid, the building and its occupants make use of data analysis, sharing the necessary information, facilitating real-time coordination and promoting balance between construction, people, and nature (Georgievski et al., 2017).

\subsubsection{Energy Performance of Buildings Directive}

The differences between the criteria of the different assessment tools make the definition of "Sustainable Construction" subjective and makes it difficult to compare the results obtained from each of the methodologies (Mateus and Bragança, 2011). In this context, the International Organization for Standardization (ISO) and the European Committee for Standardization (CEN) have been active in producing standards (eight and eleven respectively) for the environmental and sustainability assessments of buildings.

Considering founding programs, it is possible to highlight Horizon 2020, which is the biggest EU Research and Innovation program ever, over seven years (2014 to 2020).

The European Union established demanding targets to be achieved by 2020, 2030 and 2050: reduction of GHG emissions; the share of renewable energy consumption; energy saving compared with the business-as-usual scenario; and share of renewable energy in the transport sector.

Regarding legislation, there are been published directives and standards about building materials (ISO/EN 15804), construction and demolition waste (Directive 2008/98/EC) and indoor environment quality (EN 15251). Although, related to sustainable buildings the legislation is mainly focused on energy: Energy Performance of Buildings Directive (2010); and Energy Efficiency Directive (2012).

\subsection{2 nZEB - nearly Zero Energy Building}

The Energy Performance of Buildings Directive (EPBD, 2010/31/EC) introduced the definition of near Zero Energy Buildings (nZEB) as a building with very high energy performance where the nearly zero or very low amount of energy required should be extensively covered by renewable sources produced on-site or nearby. It requires that nZEB are built in member states from 2018 (in the case of public buildings) and 2020 (in the case of all buildings). Each member state is required to define the energy consumption required to achieve nZEB (Figure 1).

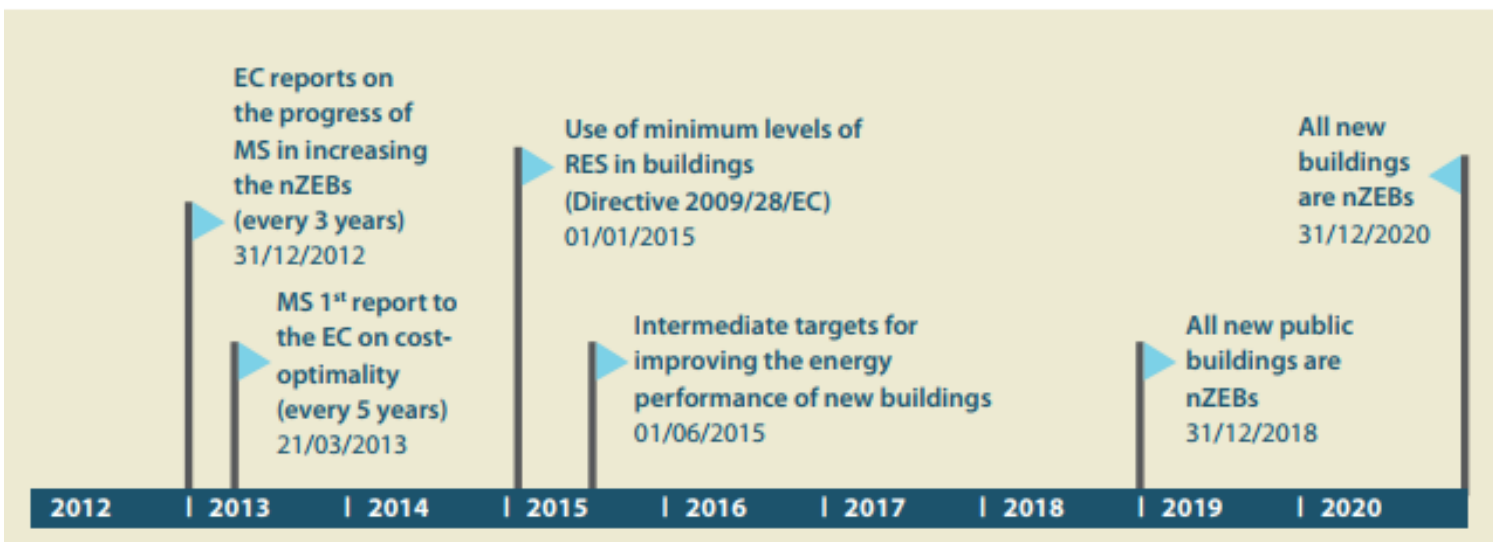

Figure 1 - Key years for nearly Zero-Energy Buildings (Directive 2010/31/EC) (EPISCOPE, 2014) 
The EPBD also establishes a benchmarking system (the principle of 'cost-optimality') to guide the Member States in setting energy performance requirements contained in national or regional building codes and keeping them under regular review. Under the EPBD, costoptimality sets the minimum level of ambition for both building renovation and new buildings. National minimum energy performance requirements are to be reviewed every five years and strengthened if they are significantly less ambitious than the national cost-optimal levels.

A complementary objective in national NZEB implementation is the integration of renewable energy sources. Directive 2009/28/EC of the European Parliament and of the Council (the "RES Directive") requires the Member States to introduce in their building regulations and codes appropriate measures in order to increase the share of all kinds of energy from renewable sources in the building sector. The provisions of the EPBD drive the use of on-site renewable energy sources, as the local energy produced reduces the primary energy associated with the delivered energy. In this way, on-site renewables are part of the calculation of the energy performance of the building.

\subsection{Holistic approach to the concept of Demand Side Management}

A growing number of countries have started to consider DSM in a more holistic fashion. For this reason, the Building Sustainability Assessment (BSA) methods started to have an increasing presence in the market since 1990.

\subsubsection{Building Sustainability Assessment Tools}

The major reason, which promoted the development of systems to support environmental performance assessment of buildings, was that the countries were unable to say how sustainable a building was. This is also true for countries and design teams, which believed that they were experts in this field (Castro, Mateus, \& Bragança, 2015).

In this regard, several countries have developed their own systems for sustainability assessment adapted to their reality and presenting them as capable of guiding the overall performance of this sector. Most of these systems are based on local rules and legislation, in locally conventional construction technologies, with the default weight of each indicator set according to the actual local socio-cultural, economic and environmental contexts (Crawley \& Aho, 1999).

Among the systems and assessment tools currently available on the market it is possible to highlight some of them for increased use and accuracy: BREEAM (Building Research Establishment Environmental Assessment Method); CASBEE (Comprehensive Assessment System for Building Environmental Efficiency); DGNB (Deutsche Gesellschaft für Nachhaltiges Bauen); Green Star; HQE (Association pour la Haute Qualité Environmentale); LEED (Leadership in Energy \& Environmental Design); NABERS (National Environmental Australian Building Rating System); and SBTool (Sustainable Building Tool).

SBTool is a generic framework for rating the sustainable performance of buildings and projects, and authorized third parties can be allowed to establish adapted SBTool versions as rating systems to suit their own regions and building types. For instance, owners and managers of large building portfolios can also use it to express in a very detailed way their own sustainability requirements to their internal staff or as briefing material for competitions. 
Lastly, it can also be an educational tool, since developing benchmarks for a wide range of issues is a useful experience for graduate and post-graduate students.

In Portugal, some tools have been developed under the structure of SBTool. There are already three available, focused on the following building types: residential buildings; office buildings; and tourism buildings. In addition to buildings, a method and a tool to assess the sustainability of urban areas and urban neighbourhoods (SBTool Urban) is also available.

\section{European initiatives, legislation and incentive programmes}

Horizon2020 (H2020) focuses in the main areas of the consumers, buildings, public authorities, industry and heating and cooling with innovative financing. It follows a pathway in energy efficiency which improves market uptake measures to remove the barriers between the consumers, the market and the government by discussing financing with various initiatives to incentive sustainable policies.

Hence, it supports the transition to a secure, clean and efficient energy system for Europe, enabling a clean and efficient supply to a competitive low carbon economy, improving the environment and the efficient use of resources. It therefore envisages a climate changes resilient economy and society, sustainable management of natural resources and ecosystems and a sustainable supply to meet the needs of a growing global population within the sustainable limits of the planets, natural resources and ecosystems, generating and sharing economic and environmental benefits (Polzin et al., 2017).

Reducing energy consumption and carbon footprint, low cost, low carbon electricity supply applying low-carbon technologies like photovoltaic panels, wind energy, hydropower, geothermal energy, energy storage and renewable heating and cooling to reduce the carbon footprint with the robust decision, promote the public engagement. However, demand response is crucial for meeting future energy needs, with the lowest possible supply and transmission capacity, contributing to system efficiency and reliability (Karunanithi et al., 2017). Thirty five percent of the H2020 budget is expected to be invested in supporting lowcarbon technologies and reliability. So, providing technical assistance for industrial and commercial or individual access to demand response can be promoted for research and innovations pathways to sustainability.

\subsection{Implementation of the nZEB requirement using the passive house standard}

In meeting the requirements of the energy performance of buildings directive, each member state can decide how best to do this. Several administrations have decided to implement nZEB through the well-established Passive House (PH) standard. For example, in the Brussels Capital Region, nZEB requirements were officially defined in 2011 and enforced from 2015 according to the principles of the $\mathrm{PH}$ standard (ref). The building sector has gradually adapted to the $\mathrm{PH}$ methodology and today nZEB requirements are mandatory for all new buildings (Figure 2). 

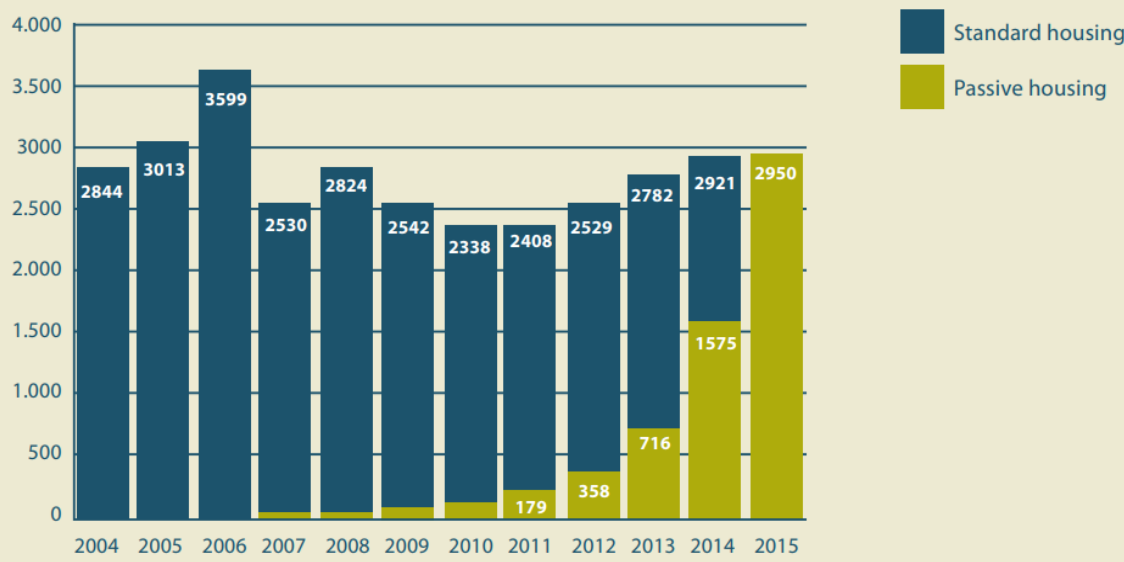

Figure 2 - Proportion of nZEB dwellings relative to total new build dwellings in Brussels

Typical performance standards for NZEB for dwellings

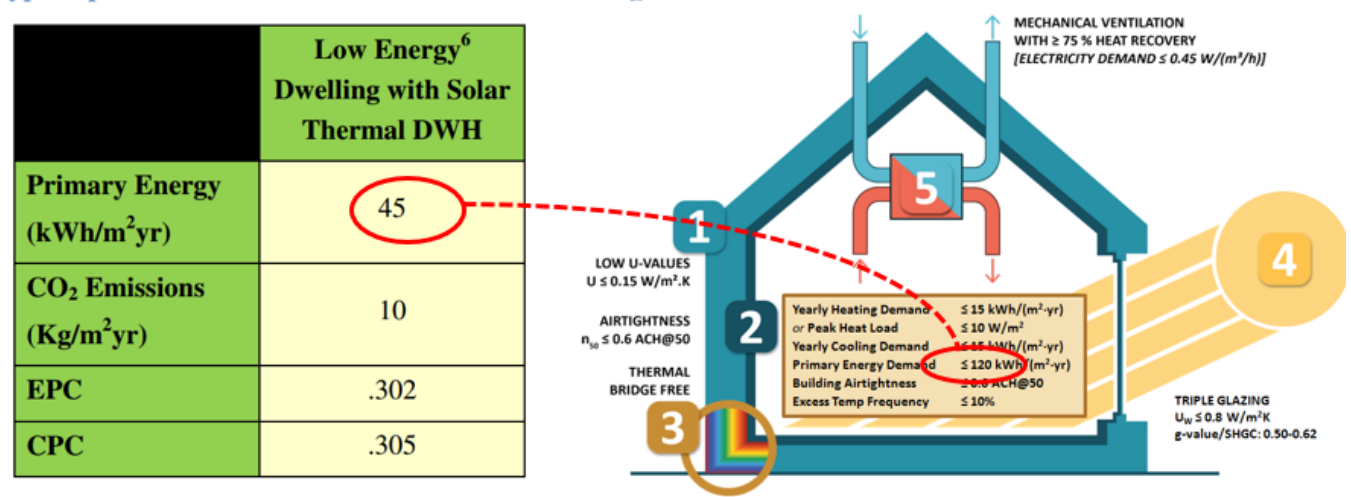

Figure 3 - Comparison of nZEB and PHPP primary energy consumption

A case study (Colclough et al, 2017a) comparing the passive house standard and the nZEB standard carried out in the Republic of Ireland found that a dwelling constructed to comply with the passive house standard and the pre-nZEB national building regulations was nZEB compliant when assessed using the National Building Energy Ratings (BER) methodology.

A key finding of the study was that care must be taken when comparing specific primary energy consumption figures. The nZEB standard in Ireland (to be finalised in 2019) requires that dwellings must consume less than $45 \mathrm{kWh} / \mathrm{m} 2 / \mathrm{a}$ (anon, 2012). To comply with the Passive House standard, dwellings must consume less than $120 \mathrm{kWh} / \mathrm{m} 2 / \mathrm{a}$ of primary energy, as determined by the Passive House planning package (PHPP) (PHI, 2016). It therefore, appeared that the nZEB standard is more stringent than the Passive House standard (Figure 3). However, this is not a like-for-like comparison. When assessed using the same national assessment methodology, the energy consumption was determined to be $24.37 \mathrm{kWh} / \mathrm{m} 2 / \mathrm{a}$, significantly below the nZEB requirements.

Further, another study (Colclough et al, 2017b) found that three quarters of the passive houses built to the minimum building regulations in Northern Ireland, were nZEB compliant with respect to primary energy consumption, without having been designed to achieve the nZEB target. 


\subsection{The Edge Office Building in Amsterdam}

The Edge Office Building in Amsterdam (Figure 4) is considered by the Building Research Establishment Environmental Assessment Method (BREEAM) to be one of the smartest building in the world, with its' high BREAAM score (98.36\%), highlighting the possibilities of new construction buildings. It is a high-profile green building with a proactive approach to building management: constantly measuring, monitoring and analysing energy consumption patterns and data, making possible periodic adjustments to maintain balanced energy usage and a comfortable building environment (BREEAM, 2017).

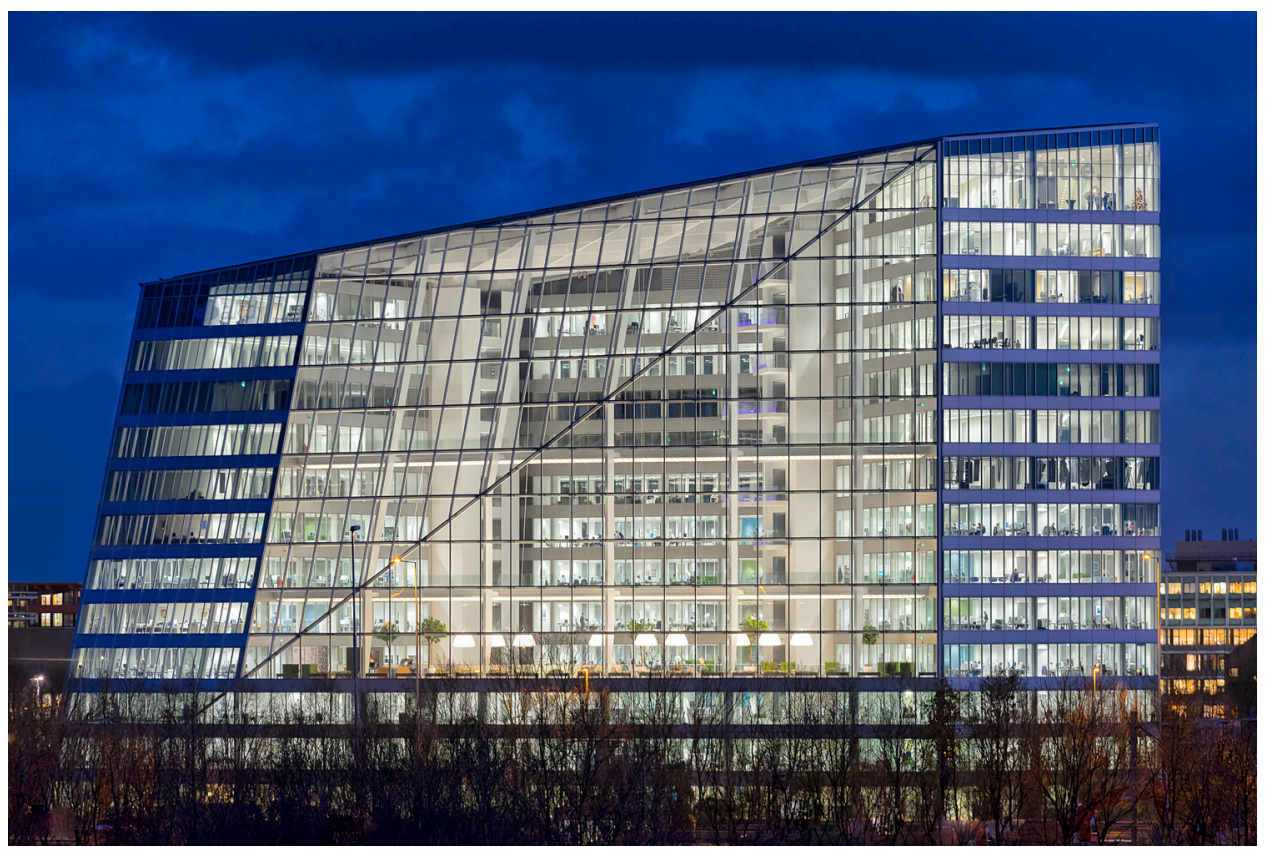

Figure 4 - Edge Office Building (Tilleman, 2014)

The building's orientation is based on the path of the sun, it creates adaptable and intelligent workspaces (Figure 5) by integrating many smart technologies like connected lights which can measure occupancy movement with sensors and Ethernet powered lighting system.

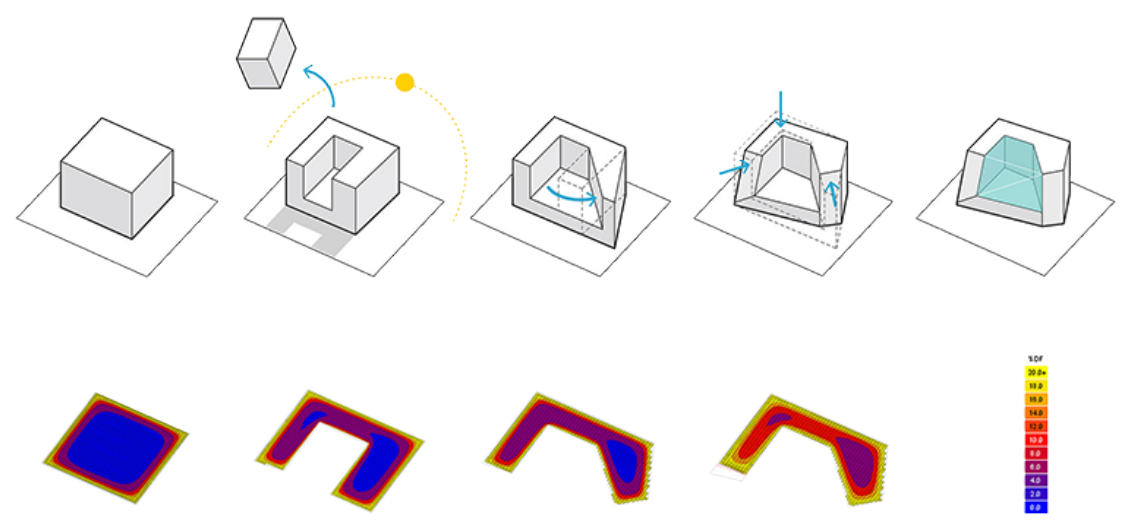

Figure 5 - Form Evolution vs. Daylight Analysis (PLP/ARCHITECTURE, 2014) 
This building can achieve the highest levels of sustainability with a collaborative working environment (Figure 6). The main advantages are improving public health, increased energy security and reduced environmental pollution, and at the same time, it has economic benefits, using renewable energies provided by wind, rain, tides, sunlight, solar heat, geothermal, hydroelectricity in combination with biofuels. It uses concepts like Demand Side Management, Energy Storage, Supply Side Management which improves the concept of Smart Grids.

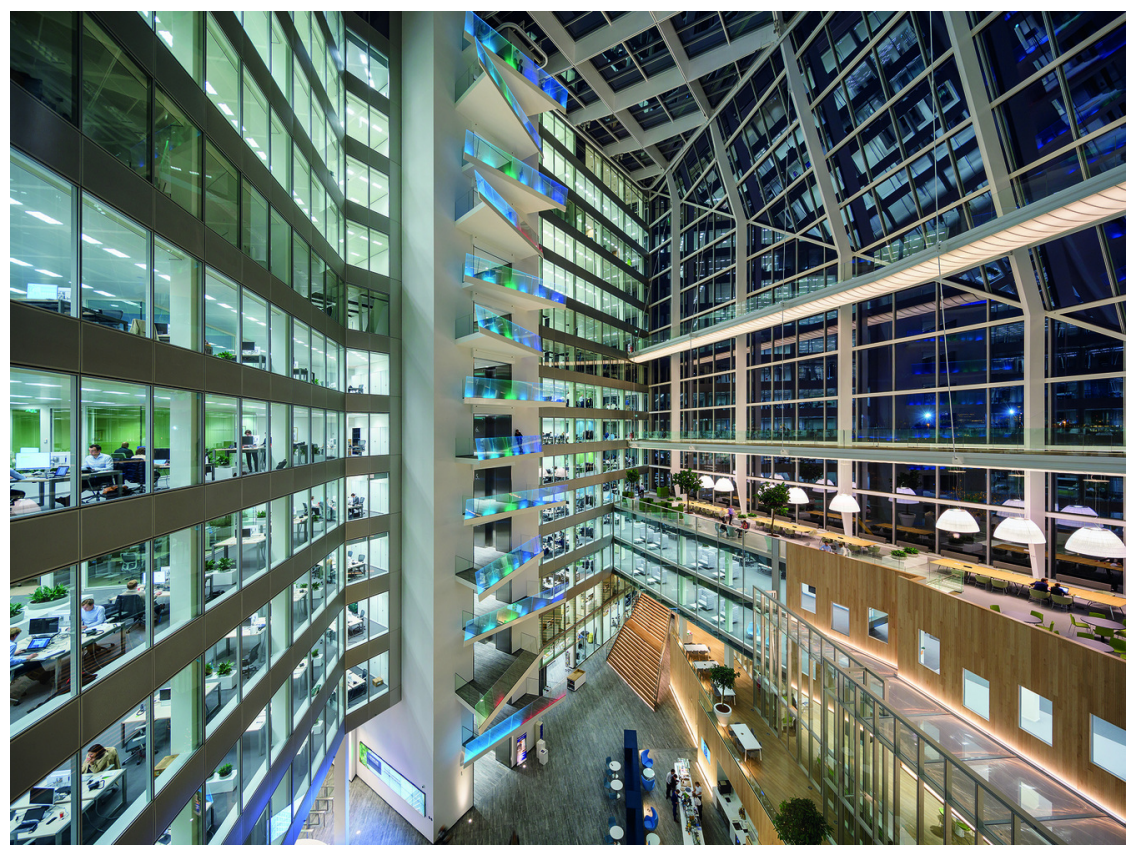

Figure 6 - Inside the Edge Office Building (Tilleman, 2014)

The Aquifer Thermal Energy Storage (TES) generates all the energy needed for heating and cooling. Rainwater is collected to flush toilets and irrigate terraces and gardens. It also applies the concept of Demand Management Education. Waste generated by each user is tracked and charged by weight, encouraging conservation, reuse and recycling in closed cycles.

The parking lot has dozens of charging stations for electric vehicles and large spaces to store bicycles. The building can enable the users (via a smartphone application) to find a parking space, find a free workstation, and customize temperature and light in their workspace. The Edge is a fully realized vision of the IoT, but it requires an enhanced approach to property management facilitated by data analysis and information obtained via data mining. This building is constantly trying to find opportunities to reduce its carbon footprint, and has become a new global benchmark for work environments, which will be enhanced and lead Europe towards a smart and decarbonized building stock by 2050 using systems such as dynamic and self-learning control systems.

\subsection{Early Stage Design method to ensure dwellings sustainability}

Research shows that most relevant decisions regarding buildings performance occur during early design stages (Kohler and Moffatt, 2003, Son and Kim, 2015). These stages are like blank pages where anything can be drawn, enabling an easier implementation of new solutions to improve social and environmental performances, without compromising the economic side (Bragança et al, 2014). Introducing sustainability concerns early in the design improves optimisation of project resources and the improvement of environmental 
performance occurs at lower costs, as these tend to increase as the design evolves (ECDG, 1999).

Sustainable design requires an integrated design process (IDP) and a more involved approach rather than a conventional one (Trumpf, 2007). IDP aims to aid design teams avoiding sub-optimal design solutions (Larsson, 2009). In IDP, project goals are set early in the process making it easier and cost-effective to integrate them into the design. All the interveners should work together with commitment to accomplishing the established goals, making feedback loops whenever needed.

In this sense, the most important goals should be established at the start of the project, defining targets to which the design alternatives should be compared with. This enables the identification of measurable criteria to help designers defining the solutions that would accomplish the project goals, with minimal environmental impacts and costs. When project briefing is poor or incomplete the probability to fail in designing sustainable buildings increases (Son and Kim, 2015). Also, if the goals are not easily measurable and understandable, limitations and inefficacy to their achievement could occur (Deru and Torcellini, 2004). Moreover, existing BSA tools are mainly applicable in latter design stages or after construction, because assessment methods require a myriad of detailed data. This rationale depicts the importance of high quality planning and the need to have a method that enables the design team to confirm their work and aid decision making towards accomplishing the sustainable target goals.

Taking this into account, a support design method and tool is being developed to support designers building more sustainable buildings, from early design stages, by alerting them to how sustainability is deeply connected to all design criteria, constraints and decisions. It shall allow the project team to compare the sustainable performance of different design solutions and verify which is the most sustainable. This procedure enables both quantification of each alternative's performance and aid decision-making through comparison of those alternatives' sustainable behaviour at each indicator level. The approach established has the following premises: (i) be simple and easy to use; (ii) be in line with international standards for sustainable construction; (iii) embrace the three sustainability dimensions; (iv) allow simultaneity of quantitative and qualitative criteria and; (v) give required guidance to understand the implications of sustainability in the design.

The tool follows the workflow presented in Figure 7 and is structured in following broad categories: (i) Materials and Resources - comprises the materials life cycle environmental impact and the efficient use of resources; (ii) Wellbeing - consisting of inhabitants' health and comfort indicators and in the building's functionality; (iii) Life Cycle Costing - covering investment, operational and end-of-life costs; (iv) Location - encompassing the site conditions, ecology and social constraints; (v) Technical and Management - accounting for project quality and management.

Each of these categories is further divided into one or two stages. Each stage represents a sustainability indicator to be evaluated. A total of twenty-one indicators were distributed to these categories. Designers can select the ones to be evaluated and the order to do so.

Unlike existing BSA tools, this design support method does not weight nor aggregate the performance achieved in each indicator; results are displayed individually, as mid-point indicators. These are presented in three ways: the first two, graphically and with a small 
description, appear in the indicators specific form; while the third summarizes the results of all indicators being displayed in the tool's first page.

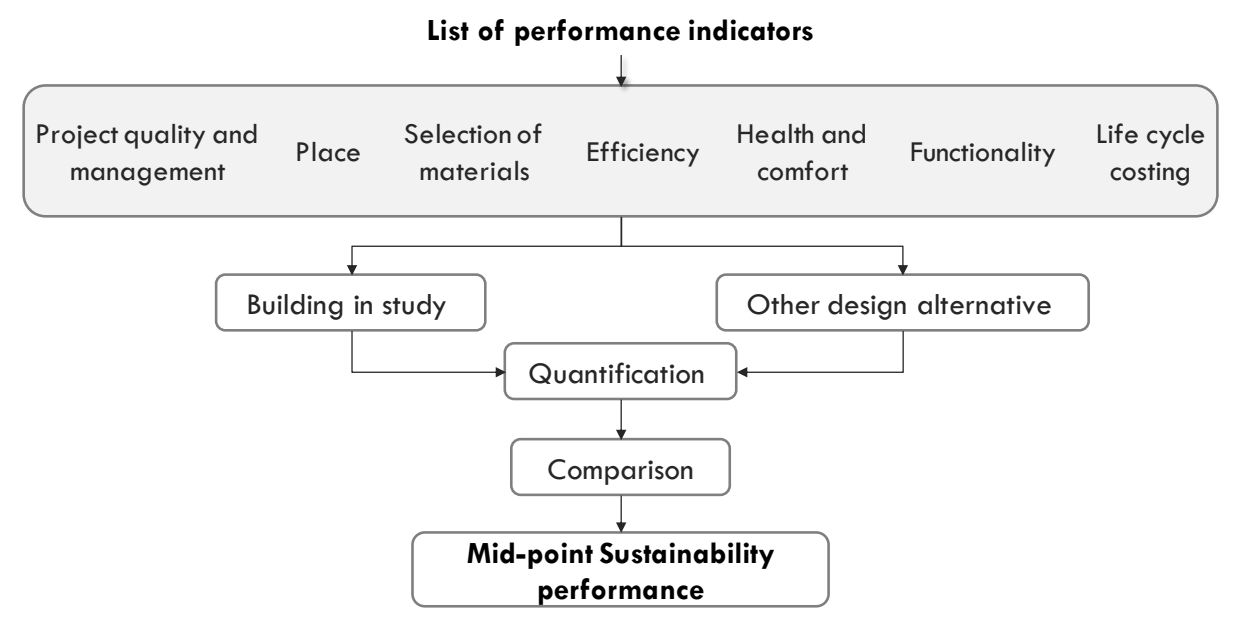

Figure 7. Early design sustainability support method workflow

\section{Conclusions}

A resilient environment, society and economy, with responsible and sustainable demand management, promotes an efficient supply and is more adapted to the constant population increase, creating healthy ecosystems and ensures the sustainability of planet Earth and its natural resources. Therefore, it is essential to foster research into dynamic and disruptive methods that promote a set of ideas that encourage the promotion of voluntary and sustainable change by all building environment life cycle stakeholders, by promoting consumption reduction and energy efficiency.

Ensuring producer responsibility, as well as the development of educational information networks and the sharing of experiences among different stakeholders, are the best ways to achieve the sustainability of the built environment. This is achieved by fostering the circular economy and by making clear links between human rights and duties, especially in the urban environment. In this way, the promotion of responsible demand management, by providing technical and qualified assistance at an individual, commercial and industrial level, is important in addition to the continued development of disruptive approaches towards sustainability.

The passive design of buildings, the creation of flexible, adaptable and intelligent spaces, through the integration of monitoring technologies, are key enablers that will support the revision of the EPBD, (which was approved with the majority of votes in the European Parliament) to ensure the correct indices are used for new constructions or significant energy refurbishments.

The circularity of these concepts promotes the sustainability of all energy networks, contributing to the development of buildings with zero emissions and improving the social and environmental behaviour of their stakeholders. Thus, optimum life cycle cost concepts, coupled with research based on social performance, promote flexibility and temporal management of the legal regime for urban rehabilitation, contributing to the urban resilience to natural disasters and climate change. 


\section{Acknowledgement}

This work scope is within InPath-TES - Innovation Pathways for Thermal Energy Storage - a European project funded by the EU Framework Programme for Research and Innovation Horizon 2020 - with the grant agreement n. 657466.

\section{References}

Attia, S., Gratia, E., De Hende, A., Hensen, J. (2012). Simulation-based decision support tool for early stages of zero-energy building design, Energy Build, 49, 2-15.

Barreto, L., Makihira, A., Riahi, K. (2003). The hydrogen economy in the 21st century: a sustainable development scenario, International Journal of Hydrogen Energy, 28, 267-284.

Bergaentzlé, C., Clastres, C., Khalfallah, H. (2014). Demand-side management and European environmental and energy goals: An optimal complementary approach, Energy Policy, 67, 858-869.

BPIE (2014). Retrieved from http://episcope.eu/fileadmin/episcope/public/docs/reports/EPISCOPE_SR1_NewBuildings InTypologies.pdf

Bragança, L., Vieira, S., and Andrade J., 2014. "Early Stage Design Decisions: The Way to Achieve Sustainable Buildings at Lower Costs." The Scientific World Journal, 2014(8).

BREEAM (2017). BREEAM home page. Retrieved from http://www.breeam.com/index.jsp?id=804

Brown, T. J., Mowen, J. C., Donavan, D.T. ve Licata, J. W. (2002). The customer orientation of service workers: personality trait effects on self and superior performance raitings, Journal of Marketing Research, 39(1), 110- 119.

Castro, M. F., Mateus, R., \& Bragança, L. (2015). A critical analysis of building sustainability assessment methods for healthcare buildings. Environment, Development and Sustainability, 17(6), 1381-1412. http://doi.org/10.1007/s10668-014-9611-0

Colclough, S.M., O'leary, T., Hewitt, N.J. \& Griffiths, P. (2017). The near Zero Energy Building standard and the Passivhaus standard - a case study, Design to Thrive: Proceedings Volume 1, PLEA 2017 conference, 3rd to 5th July 2017, NCEUB 2017. ISBN 978-0-9928957-5-4, pp. 385-392.

Colclough, S., Griffiths, P. and Hewitt, N.J. (2017). Winter performance of certified passive houses In a Temperate Maritime Climate - nZEB Compliant? Mediterranean Green Buildings and Renewable Energy Forum, Jul 31 to Aug 32017.

Crawley, D., \& Aho, I. (1999). Building environmental assessment methods: applications and development trends. Building Research \& Information, 27(4-5), 300-308. http://doi.org/10.1080/096132199369417

Dabur, P., Singh, G., Yadav, N.K. (2012). Electricity Demand Side Management: Various Concept and Prospects, International Journal of Recent Technology and Engineering, Volume-1.

Deci, E.L. \& Ryan, R. M. (1991). A motivational approach to self: Integration in personality. In R. Diensbier (Ed.), Nebraska Symposium on Motivation: Vol. 38. Perspectives on motivation (pp. 237-288). Lincoln: University of Nebraska Press.

Deru, M., and Torcellini P., 2004. "Improving Sustainability of Buildings Through a Performance-Based Design Approach." World Renewable Energy Congress VIII and Expo, Denver, USA, 29 August to 3 September, 2004. 
Din, A., Brotas, L. (2016). Exploration of life cycle data calculation: lesson from a Passivhaus case study, Energy and Buildings, 82-92.

Directive 2010/31/EU of the European Parliament and of the Council of 19 May 2010 on the Energy Performance of Buildings.

Directive 2012/27/EU of the European Parliament and of the Council of 25 October 2012 on Energy Efficiency, amending Directives 2009/125/EC and 2010/30/EU and repealing Directives 2004/8/EC and 2006/32/EC.

Duballet, R., Baverel, O., Dirrenberger, J. (2017). Classification of building systems for concrete 3D printing, Automation in Construction, 83, 247-258.

European Commission Directorate General XVII for Energy (ECDG), 1999. “A green Vitruvius: Principles and practise of sustainable architectural design". 1st Edition ed. London: James \& James Science Publishers.

EU, 2016. European Commission -Environment - Sustainable buildings. Retrieved November 11, 2016 (http://ec.europa.eu/environment/eussd/buildings.htm).

Ford, R., Pritoni, M., Sanguinetti, A., Karlin, B. (2017). Categories and functionality of smart home technology for energy management, Building and environment, 123, 543-554.

Georgievski, I., Nguyen, T.A., Nizamic, F., Setz, B., Lazovik, A., Aiello, M. (2017). Planning meets activity recognition: Service coordination for intelligent buildings, Pervasive and Mobile Computing, 38, 110-139.

Hair, J.F., Anderson, R.E., Tahtam, R.L. ve Black, W.C. (1998). Multivariate data analysis, Fifth Edition, New Jersey: Prentice-Hall International, Inc.

Herczeg, M., McKinnon, D., Milios, L., Bakas, I., Klaassens, E., Svatikova, K., Widerberg, O., 2014. "Resource efficiency in the building sector" ECORYS Final Report. Copenhagen Resource Institute. Rotterdam.

Karunanithi, K., Saravanan, S., Prabakar, B.R., Kannan, S., Thangaraj, C. (2017). Integration of demand and Supply Side Management strategies in Generation Expansion Planning, Renewable and Sustainable Energy Reviews, 73, 966-982.

Kohler, N., and Moffatt S., 2003. "Life-cycle analysis of the built environment." UNEP Industry and Environment, pp. 17-21.

Kylili, A., Fokaides, P.A. (2017). Policy trends for the sustainability assessment of construction materials: A review, Sustainable Cities and Society, 35, 280-288.

Larsson, Nils. 2009. "The Integrated Design Process: History and Analysis." Canada, 21 August, 2009.

Lazarevic, D., Valve, H. (2017). Narrating expectations for the circular economy: Towards a common and contested European transition, Energy Research \& Social Science, 31, 60-69.

Lehmann, S. (2013). Low carbon construction systems using prefabricated engineered solid wood panels for urban infill to significantly reduce greenhouse gas emissions, Sustainable Cities and Society, 6, 57-67.

Mateus, R. and Bragança L., 2011. "Sustainability Assessment and Rating of Buildings: Developing the Methodology SBToolPT-H.” Building and Environment 46(10), pp.196271.

Muñoz, P., Morales, P., Letelier, V., Muñoz, L., Mora, D. (2017). Implications of Life Cycle Energy Assessment of a new school building, regarding the nearly Zero Energy Buildings targets in EU: A case of Study, Sustainable Cities and Society, 32, 142-152.

PHI, 2016-last update, Passive House Planning Package (2016). Retrieved from https://passipedia.org/planning/calculating_energy_efficiency/phpp__the_passive_house_planning_package. 
PLP/ARCHITECTURE (2014). Retrieved from http://www.plparchitecture.com/theedge.html

Polzin, F., Sanders, M., Täube, F. (2017). A diverse and resilient financial system for investments in the energy transition, Current Opinion in Environmental Sustainability, 28, 24-32.

Rahimpour, Z., Facccani, A., Azuatalam, D., Chapman, A., Verbic, G. (2017). Using Thermal inertia of buildings with Phase Change Material for Demand Response, Energy Procedia, 121, 102-109.

Ronald Tilleman (2014). Retrieved from http://www.tilleman.nl

Smale, R., Vliet, B.V., Spaargaren, G. (2017). When social practices meet smart grids: Flexibility, grid management, and domestic consumption in The Netherlands, Energy Research \& Social Science, 34, 132-140.

Son, H., and Kim C., 2015. "Early prediction of the performance of green building projects using pre-project planning variables: data mining approaches." Journal of Cleaner Production 109, pp. 144-151.

Strbac, G. (2008). Demand Side Management: Benefits and challenges, Energy Policy, 36, 4419-4426.

Trumpf, H. 2007. "An approach for an Integrated Design Process focussed on Sustainable Buildings." Action C25: Sustainability of Constructions - Integrated Approach to Life-time Structural Engineering, Lisbon, Portugal.

UNEP, 2016. "United Nations Environment Programme environment for development - Why Buildings?" Retrieved November 8, 2016 (http://www.unep.org/sbci/AboutSBCI/Background.asp).

Vermesan, O., Friess, P. (2013). Internet of things - Converging Technologies for Smart Environments and Integrated Ecosystems, Aalborg: River Publishers.

WWF. 2016. Living Planet Report ${ }^{\circledR}$ 2016. Risk and Resilience in a new era, WWW International, Gland, Switzerland. ISBN: 978-2-940529-40-7 